\title{
The young, educated, minorities and the poor move out from south central Ethiopia.
}

\author{
Wubegzier Mekonnen ${ }^{1 a}$ and Alemayehu Worku ${ }^{b}$ \\ School of Public Health, College of Health Sciences, Addis Ababa University, \\ Addis Ababa, Ethiopia. \\ wubegzierm@gmail.com, Tele: +251911668606, Box:9086,
}

\begin{abstract}
High population growth fragmented rural landholdings leading to low harvests and crop yields per acre per annum creating surplus labour that may resort to migration as a coping mechanism in least developing countries including Ethiopia. The main aim of the study is to assess trends and differentials of out-migration in south central Ethiopia. The Butajira demographic surveillance system database from 1987 to 2008 was used to conduct event history analysis.

There were 3.97 out-migrations per 100 person years. Probability of out-migration was higher among males, teenagers, the youth, completed primary and secondary plus education; not in marital union; Christians, urbanites; lived in rented and owed house compared to their respective counterparts. The higher chances of out-migration among these groups may have social and economic significance.
\end{abstract}

\section{Resume}

Exploitations rurales fragmentées de croissance élevée de la population conduisant à de faibles récoltes et les rendements des cultures par acre par an travail création de surplus qui peut recourir à la migration comme un mécanisme d'adaptation dans les pays en développement les moins dont l'Ethiopie . L'objectif principal de l'étude est d'évaluer les tendances et les écarts de l'émigration dans le centre sud Ethiopie. La base de données démographiques du système de surveillance Butajira 1987-2008 a été utilisé pour effectuer une analyse de l'historique des événements . Il y avait 3,97 out -migrations pour 100 années-personnes. Probabilité d'émigration était plus élevé chez les hommes, les adolescents, les jeunes, complété primaire et secondaire ainsi que l'éducation ; pas dans l'union conjugale ; Chrétiens , les citadins ; vécu dans la maison louée et due par rapport à leurs homologues respectifs. Les plus grandes chances de l'émigration parmi ces groupes peuvent avoir une importance sociale et économique .

Key Words: Butajira, Demographic Surveillance System, Ethiopia

\section{Introduction}

People might move from their home places because of unsuitable living condition and better opportunities elsewhere. Unequal access to assets, income, education and access to properties such as land, ox or house ownerships may change the rates of human migration (Bilsborrow and Winegarden 1985, Bainame, Letamo et al. 2002). Natural and manmade calamities, a dearth of employment opportunities, and civil strife push residents to leave for an area where there are no such problems (Kloos 1982, Massey and Zenteno 1999). Communication with out-migrant family members, friends and neighbours often motivate residents at their place of origin to migrate to these areas where their relatives and friends are living (Massey 1990, Fussell and Massey 2004, Fleischer 2007, Poveda 2007).
Individuals usually decide to migrate after making a risk-benefit analysis (Kline 2003).

Rates of migration varied across communities and involved movement of individuals, families, or groups from one area to another. Migration plays a role in the size, composition and spatial redistribution of societies (George, Nault et al. 1991, Byass, Berhane et al. 2003). Migration studies revealed the youth, males, people who have less access to land holdings and property ownerships, minority ethnic and religious groups and educated people were at a higher probability of out-migration (Schlottmann and Herzog 1984, Zhang, Wu et al. 1997, Ram and Shin 2007, Kaushik, Jaiswal et al. 2008, Zorlu 2009). Also, formation and dissolution of marriage, and interest in continuing education or dropping out of school were observed as reasons for out 
migration(Gurumu, Goldstein et al. 2000, Mberu 2006).

Often, migration flows increased dramatically during famines which changes population redistribution in Ethiopia (Ezra and Kiros 200I). The Guraghe area of Ethiopia is one of the most densely populated zones in the country (Shamebo, Sandstrom et al. 1992, Regassa and Yusufe 2009). Rapid population growth fragments rural landholdings with low cropping intensity and low yields thus creating surplus labour with a high propernsty to migration as a coping mechanism (Ullah 2004). Guraghes have been found in most urban areas in Ethiopia because of the unfavourable living condition in their area of origin. A nationally representative sample survey showed the population and environmental pressures force many residents to look for better livelihoods mostly in urban centres in Ethiopia(Gurumu, Goldstein et al. 2000). An earlier study indicated that about $48 \%$ of individuals migrated in or out of Butajira Demographic Surveillance Area (DSA) at some stage over a tenyear period, as recorded in monthly household visits between 1987 and 1996. There was also a net incidence of migration into the urban area, particularly among young adults (Byass, Berhane et al. 2003). There are reports indicating that economic developments have been witnessed in Ethiopia in recent years (UNDP 20I4). The focus of the growth and transformation plan of the country is agriculture lead industrialization (MoFED 20I3) though the impact of such a policy on the rural youth, educated and the poor is not yet explored. The focus of this study was on out-migration of people from 10 sampled neighbourhoods in south central Ethiopia. It aimed to measure the incidence of out-migrations among different population groups. Moreover, the relative probability of out migration across various population groups was examined.

\section{Materials and Methods}

The study was conducted in Butajira district of Guraghe zone which is about $135 \mathrm{kms}$ South of Addis Ababa. Guraghe zone was located in the Southern Nations, Nationalities and Peoples region of Ethiopia. The study area encompassed arid and semi-arid geographical areas. The district was predominantly inhabited by different clans of the Guraghe tribe. Silti and Mareko were the other major ethnic groups living in the district. The majority of residents in the district are Muslims followed by Orthodox Christians. The district had been stricken by cyclical famines. The time between one and the next cycle of famine had been shortened nowadays (Ullah 2004)
The study design was a longitudinal study design. The Butajira Demographic Surveillance System (DSS) launched in 1987 (Berhane, Wall et al. 1999) continuously recorded births, deaths, changes in marital and migratory status in sampled 9 rural and I urban neighbourhoods (kebeles). A series of studies conducted using the Butajira surveillance database revealed a variety of findings in relation to the three components of population change. Total fertility was about 5.3 children per woman in 2009 (Mekonnen and Worku 20II). Though the population in the study communities has undergone a complex epidemiologic transition the crude mortality was documented to be 13.5 per 1000 person years in 2004 (Berhane, Wall et al. 2008). Moreover about $48 \%$ of adults in the study communities have been experienced migration in their life time (Byass, Berhane et al. 2003).

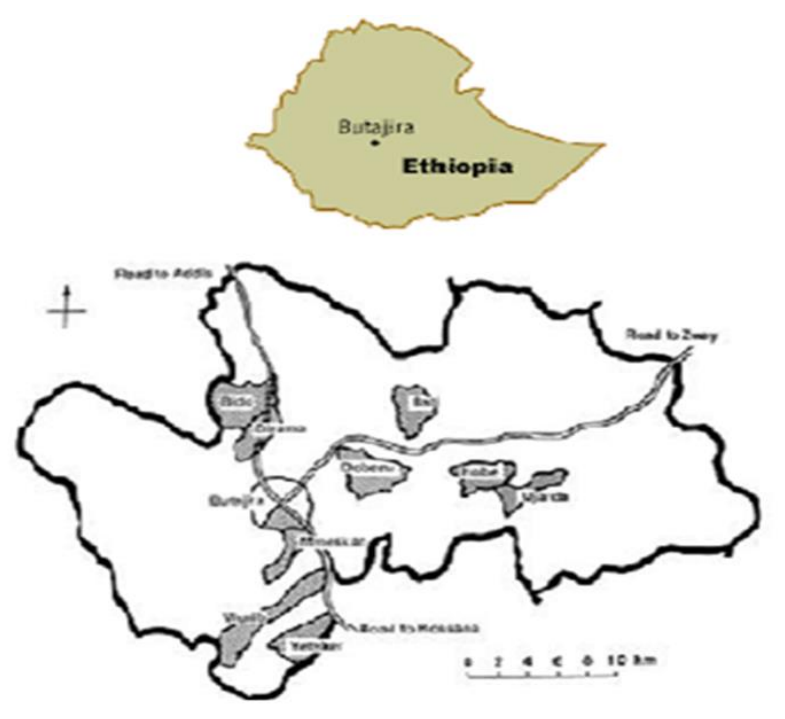

Figure I: Map showing the relative location of study area (Only a quarter of the Butajira town is urban.

The 10 sampled Kebeles based on probability proportionate to size technique has been the DSA of the Butajira DSS. A baseline population and housing census was conducted at the beginning of the surveillance in 1987. Then, a continuous registration of events was conducted monthly up to 1999 and quarterly thereafter. Data were captured by trained village based enumerators who paid visits to all households within the DSA. One field supervisor was assigned in 2 Kebeles to re-interview at least 5 per cent of the households and undertake validity and consistency checks. The Butajira DSS has been described in detail elsewhere (Shamebo, Sandstrom et al. 1993).

Data were originally entered into a software designed using the DBase IV platform to manage 
longitudinal data. The software automatically generates unique identifiers and checks consistency for each household and individual under follow-up. It also helps to define the episodes of exposures. For instance a person could be illiterate for certain period of time and literate thereafter. The Butajira DSS longitudinal database in the period of 1987 and 2008 was extracted for this study. Data cleaning and analysis were done using STATA version II.

The main interest in this study is out migration. A member of the Butajira DSS has been considered as an out migrant if the individual moved out of the DSA

With an intension of living elsewhere or wouldn't come back within 6 months though the person did not have such intention.

A censoring variable was coded as I if an individual moved out of the DSA and 0 otherwise, while duration episodes of exposure (in years) was computed from dates of entry and exit into an open cohort. Entry into the demographic surveillance system could be possible through in-migration, birth and dejure residence in the DSA during the baseline census enumeration. Whereas, exit from the surveillance system happened through death, outmigration or end of the follow-up. The difference between dates of entry and exit was a measure of the duration of exposure. Besides covariates including age, sex, educational status, marital status, religion, oxen and house ownership were cleaned for inconsistencies and recoded.

Person times of exposure were computed using event history analysis technique since the database was longitudinal in nature. Life Table and out migration incidence rates were computed for various categories of population characteristics. Smoothed out-migration age pattern by residential ecology and sex groups was also revealed graphically. A Poisson regression model was used to examine probabilities of out-migration taking into account individual exposure time. This model therefore reflects the influence of all individual person-time risk exposure before out-migration for those who out-migrated, compared with the same individual risk exposure for those who never moved out. The association of various covariates with out-migration was ascertained by out-migration Incidence Rate Ratio (IRR) along with a $95 \%$ confidence interval.

\section{Results}

There were a total of 39,679 out-migration episodes in a 999,025.97 person-years of observation which corresponds to 3.97 incidence of out migration per I 00 person- years with $95 \% \mathrm{Cl}$ of $(3.93,4.0$ I) over the 22 years study period.

High out-migration were observed among the youth aged $15-19$ and 20-29 years at an incidence rate of $7.25(7.09,7.40)$ and $6.26(61.4,6.38)$ per 100 person years of observation, respectively (Table I). On the other hand, the incidence rate of outmigration was only $1.94(1.84,2.05)$ and 2.08 (I.98, 2.18) among adults aged $40-49$ years and 50 plus years per 100 person years observation, respectively. The out-migration incidence rate had also shown sex disparity with a rate of $4.16(4.10,4.22)$ and 3.79 $(3.74,3.85)$ out-migration per 100 person years of observation among males and females, respectively. A smoothed outmigration hazard estimate age pattern in Figure I also indicated consistently higher incidence rate of out-migration for males compared to females between the ages of 20 and 50 years though the pattern was changed in the remaining age groups. The pick age of incidence of out-migration were documented at age 20 years for both sexes. 


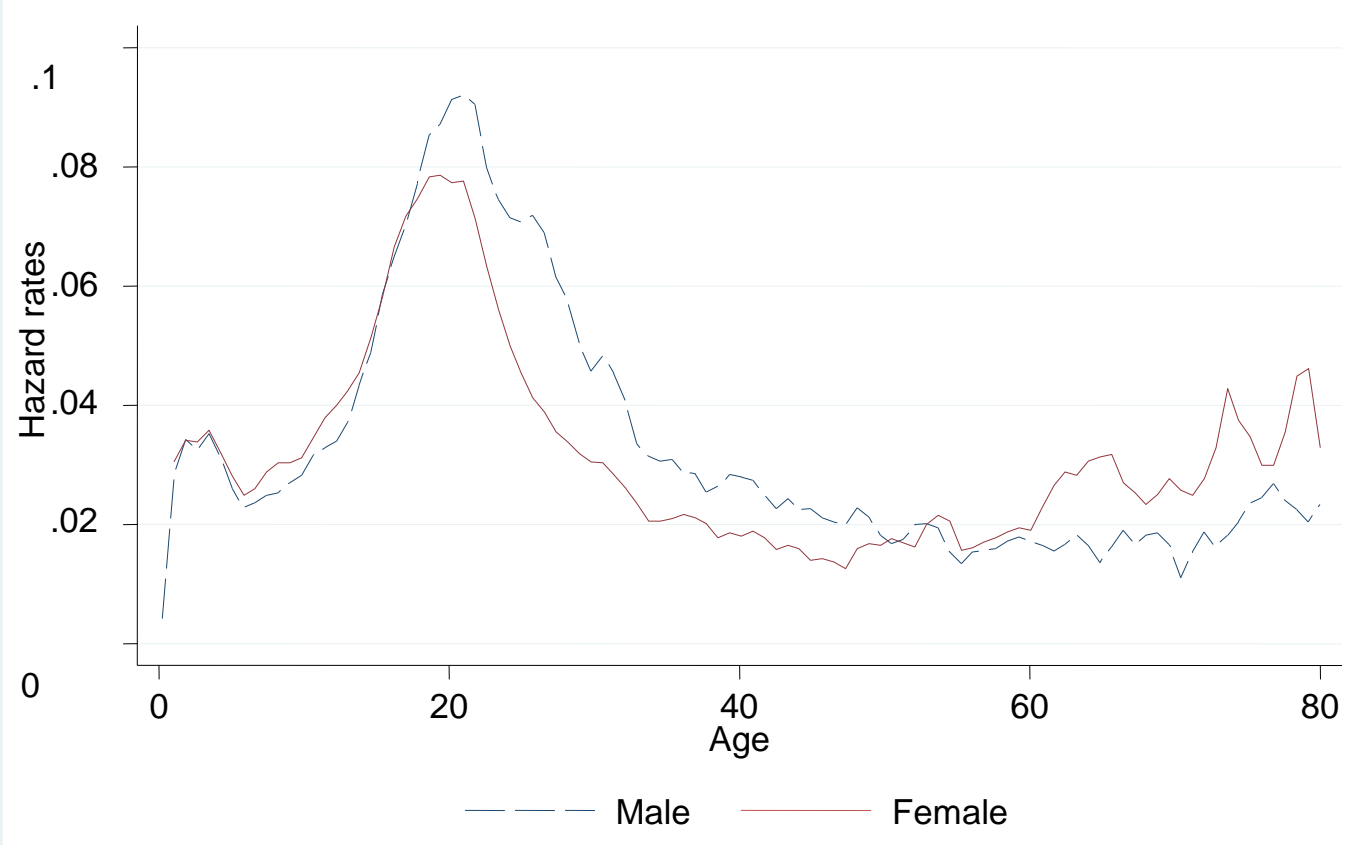

Fig 2 : Smoothed age pattern hazard estimates of out-migration by sex in Butajira from 1987-2008

An examination of the incidence of out-migration by educational status revealed different levels across categories. Out-migration was far higher among more educated residents of Butajira district with an incidence rate of 10.92 out migrations per 100 person years of observation with a $\mathrm{Cl}$ of $(10.42$, II.45) among those completed secondary plus level of education. Higher out-migration was also estimated among people who had been too young to marry and singles with an incidence rate of 7.07 $(6.97, .16)$ and $3.94(3.87,4.01)$ out migrations per 100 person years of observations, respectively. The incidence of out-migration was however very low among ever married residents showing no statistically significant difference among currently married and formerly married Butajira residents with outmigrations levels of I.4I (I.37, I.46) and I.44 (I.35, I.54) per 100 person years of observation, respectively. Among those whose religious denominations were recorded by the surveillance system, area minority Christian groups revealed the higher out-migration incidence rate 4.31 (4.23, 4.0I) per 100 person years of observation.

There was also statistically significant difference in the levels of out-migration across residential ecological areas. The incidence of out-migration was higher among urban Butajira residents with a level of $5.58(5.48,5.68)$ and lower amid highlanders with a level of 3.37 (3.32, 3.43) out migrations per 100 person years of observation. Moreover, a smoothed age pattern of the hazard of out-migration showed consistently higher incidence of outmigration in urban Butajira (Figure 2). Comparison of out-migration incidence rate in the two rural residential ecological zones documented a higher rate among highlanders up to age 20 years though the pattern was in favour of lowlanders thereafter. 


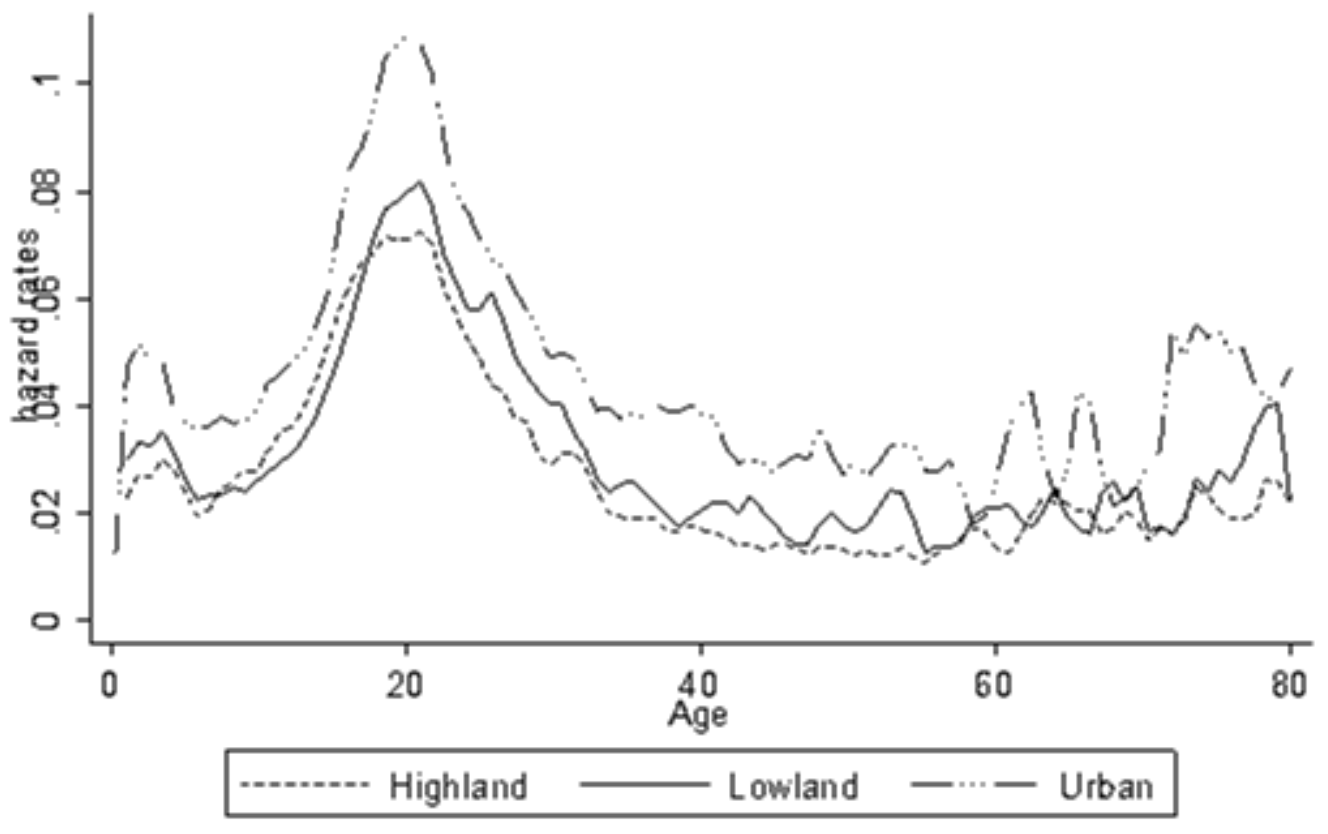

Fig 3: The Smoothed Age pattern hazard estimates of out-migration by environment in Butajira District from 1987 to 2008

Out-migration rate was also distinct across asset ownership status. The incidence rate of outmigrations was higher among residents who did not have oxen to plough their farm plot with a rate of 3.61 out migrations per 100 person years of observations with a $\mathrm{Cl}$ of $(3.54,3.67)$. The incidence of out-migration was lower among those who had the animal at a rate of $2.18(2.14,2.23)$ out migrations per 100 person years of observations. On the other hand, people living in houses obtained from relatives free of pay had the highest incidence of out migration rate of 12.74 out migrations $(12.34,13.15)$ per 100 person years of observations. The next higher out-migration incidence was observed among those who lived in rented houses with a 6.52 out migrations per 100 person years of observations with $\mathrm{Cl}$ of $(6.35,6.69)$, whereas people living in their own houses had a minimum out-migration incidence rate of 6.52 out migrations $(6.35,6.69)$ per 100 person years of observations.

Table I: Differentials of out-migration Incidence in Butajira between 1987 and 2008

\begin{tabular}{|c|c|c|c|}
\hline Factors & Person time in years & Out-migrations & $\begin{array}{lcc}\text { Incidence Rate per } & 100 \\
\text { person-years }(95 \% \mathrm{Cl}) & \\
\end{array}$ \\
\hline Age group: & 450045.91 & 14194 & $3.15(3.10,3.21)$ \\
\hline $15-19$ & $1|84| 9.77$ & 8583 & $7.25(7.09,7.40)$ \\
\hline $20-29$ & $|72960.0|$ & 10822 & $6.26(6.14,6.38)$ \\
\hline $30-39$ & 110263.57 & 3114 & $2.82(2.73,2.93)$ \\
\hline $40-49$ & $686 \mid 4.197$ & 1332 & $1.94(1.84,2.05)$ \\
\hline $50+$ & 78722.507 & 1634 & $2.08(1.98,2.18)$ \\
\hline Male & 488830.69 & 20329 & $4.16(4.10,4.22)$ \\
\hline Female & 510195.27 & 19350 & $3.79(3.74,3.85)$ \\
\hline Educational status: Never & 495774.23 & 10175 & $2.05(2.01,2.09)$ \\
\hline Primary & 52118.171 & 2253 & $4.32(4.15,4.50)$ \\
\hline Secondary plus & 15667.165 & 17|| & $10.92(10.42,11.45)$ \\
\hline Very young Children & 435466.4 & 25540 & $5.86(5.79,5.94)$ \\
\hline Marital status: Married & 305644.04 & 4322 & $1.41(1.37,1.46)$ \\
\hline Single & 320484.29 & 12616 & $3.94(3.87,4.01)$ \\
\hline Other (young to marry) & 308813.09 & 21818 & $7.07(6.97,7.16)$ \\
\hline Formerly married & 64084.55 & 923 & $1.44(1.35,1.54)$ \\
\hline Religion: Muslim & 727646.58 & 22431 & $3.08(3.04,3.12)$ \\
\hline Christian & 233791.04 & 10090 & $4.31(4.23,4.01)$ \\
\hline Other & 37588.35 & 7158 & $19.04(18.61,19.48)$ \\
\hline
\end{tabular}




\begin{tabular}{llll}
\hline Factors & Person time in years & Out-migrations & $\begin{array}{l}\text { Incidence Rate per } 100 \\
\text { person-years }(95 \% \mathrm{Cl})\end{array}$ \\
\hline Environment: Highland & 430532.45 & 14519 & $3.37(3.32,3.43)$ \\
Lowland & 351413.65 & 13042 & $3.71(3.65,3.78)$ \\
Urban & 217079.86 & 12118 & $5.58(5.48,5.68)$ \\
\hline Oxen ownership: No & $3157 \mid 7.19$ & 11389 & $3.61(3.54,3.67)$ \\
Yes & 365647.09 & 7984 & $2.18(2.14,2.23)$ \\
UK & 317661.69 & 20306 & $6.39(6.31,6.48)$ \\
\hline House ownership: Owned & 878258.46 & 29967 & $3.41(3.37,3.45)$ \\
Rented & 91200.504 & 5945 & $6.52(6.35,6.69)$ \\
Other & 29567.003 & 3767 & $12.74(12.34,13.15)$ \\
\hline Total & 999025.97 & 39679 & $3.97(3.93,4.01)$ \\
\hline
\end{tabular}

Multivariate analyses of the association of individual and household characteristics with outmigration are shown in Table 2. The probability of out-migration was $\mathrm{I} .9(\mathrm{I} .85, \mathrm{I} .96)$ and $\mathrm{I} .77$ (I.7I, I.82) times higher among teenagers ( $15-19$ years) and young adults aged 20-29 years respectively compared to children under the age of 15 years. However, the probability of out-migration was significantly lower among adults over the age of 30 years in reference to the same group. The likelihood of out-migration was about six percent lower among females compared to males with an IRR of 0.94 (0.92, 0.96).

An examination of the probability of out-migration by educational status showed a pronounced likelihood as educational level increased. The chance was $1.23(1.17,1.29)$ and $2.82(2.66,2.98)$ times higher among those attained primary and secondary plus levels respectively compared to those who had never been into a formal education.

On the other hand, the probability of outmigration was I.55 (I.49, I.62) and I.47 (I.37, I.58) times higher among singles and those who were formerly married but not in current marital union respectively, that did not have stronger familial ties, compared to those in current marital union. Children less than 15 years of age were $0.94(0.90,0.99)$ times less likely to move out from their usual place of abode compared to married ones in Butajira district. Besides, the area minority Christians had an outmigration chance that was 1.29 (I.26, I.32) times higher compared to the area majority Muslims.

Informed urbanites had the higher propensity of out migration compared to rural highland residents. The likelihood of out-migration was I.47 (I.36, I.58) times higher compared to rural highlanders. There was however no statistically significant difference in out-migration rate ratios between lowlanders and highlanders in Butajira district controlling for other variables.

Meanwhile, the association of oxen ownership and out-migration was marginally significant 1.03 ( 1.00 , I.06). However, the probability of out-migration was 1.58 (I.52, I.64) and 2.11 (2.04, 2. I8) times higher among persons who lived in a rented house and obtained rent free from a relative compared to a those lived in a house owned by a household member.

Table 2: Association of socio-demographic factors with outmigration in Butajira between 1987 to 2008

\begin{tabular}{|c|c|c|c|c|}
\hline \multirow[t]{2}{*}{ Variable } & \multicolumn{2}{|c|}{ Person times of exposure in years } & \multicolumn{2}{|c|}{$\begin{array}{l}\text { Out-migration Incidence Rate ratios } \\
\text { (95\% confidence interval) }\end{array}$} \\
\hline & Out-migrants & Non-migrants & Crude & Adjusted \\
\hline Age group: & 25343.55 & 370570.8 & 1.00 & 1.00 \\
\hline $15-19$ & I 1354.89 & $|0083| .4$ & $2.14(2.09,2.19)$ & $1.90(1.85,1.96)$ \\
\hline $20-29$ & 16036.88 & $|478| 4.6$ & $1.97(1.92,2.02)$ & $1.77(1.71,1.82)$ \\
\hline $30-39$ & 4902.728 & 97972.48 & $0.89(0.86,0.93)$ & $0.93(0.89,0.97)$ \\
\hline $40-49$ & 2297.157 & 6745.73 & $0.53(0.50,0.56)$ & $0.63(0.60,0.67)$ \\
\hline $50+$ & 3531.126 & 90381.68 & $0.50(0.47,0.52)$ & $0.58(0.55,0.6 \mathrm{I})$ \\
\hline Male & 31625.26 & 428882.8 & 1.00 & 1.00 \\
\hline Female & 31841.07 & 445133.9 & $0.92(0.90,0.93)$ & $0.94(0.92,0.96)$ \\
\hline Education status: Never & 15622.35 & 324105.9 & 1.00 & 1.00 \\
\hline Primary & 2876.695 & $3|730.8|$ & $2.2 I(2.1 I, 2.3 I)$ & $1.23(1.17,1.29)$ \\
\hline Secondary plus & 1917.728 & 9717.437 & $5.75(5.44,6.09)$ & $2.82(2.66,2.98)$ \\
\hline Very young children & 43049.56 & 508462.6 & $1.46(1.43,1.49)$ & $1.44(1.40,1.48)$ \\
\hline
\end{tabular}




\begin{tabular}{|c|c|c|c|c|}
\hline \multirow[t]{2}{*}{ Variable } & \multicolumn{2}{|c|}{ Person times of exposure in years } & \multicolumn{2}{|c|}{$\begin{array}{l}\text { Out-migration Incidence Rate ratios } \\
\text { (95\% confidence interval) }\end{array}$} \\
\hline & Out-migrants & Non-migrants & Crude & Adjusted \\
\hline Marital status: Married & $54 \mid 4.779$ & 179630.8 & 1.00 & 1.00 \\
\hline Single & 16590.09 & | 88273.7 & $2.50(2.41,2.58)$ & $1.55(\mathrm{I} .49, \mathrm{I} .62)$ \\
\hline Others (young to marry) & 40279.68 & 472495.6 & $1.59(1.54,1.64)$ & $0.94(0.90,0.99)$ \\
\hline Formerly married & 1181.789 & 33616.6 & $1.14(1.07,1.22)$ & $1.47(1.37,1.58)$ \\
\hline Religion: Muslim & 35758.36 & $6464 \mid 5.1$ & 1.00 & 1.00 \\
\hline Christian & $15 \mid 87.48$ & 197603.6 & $\mathrm{I} .47(\mathrm{I} .43, \mathrm{I} .50)$ & $1.29(1.26,1.32)$ \\
\hline Others & 12520.49 & 29998.01 & $4.96(4.82,5.10)$ & $4.71(4.56,4.87$ \\
\hline Environment: Highland & 24883.25 & 377841.8 & 1.00 & 1.00 \\
\hline Lowland & $207 \mid 4.45$ & 311713.1 & $1.11(1.08,1.14)$ & $1.00(0.97,1.02)$ \\
\hline Urban & 17868.68 & 184461.9 & $1.86(1.81,1.91)$ & $1.18(1.15,1.22)$ \\
\hline Oxen ownership: & $15108.4 \mid$ & 291140.9 & 1.00 & 1.00 \\
\hline Yes & $1 \mid 230.78$ & 237562.7 & $0.82(0.80,0.85)$ & $1.04(1.01,1.07)$ \\
\hline UK & 37127.14 & 345313.1 & $1.29(1.26,1.32)$ & $1.13(1.10,1.16)$ \\
\hline \multicolumn{5}{|l|}{ House ownership: } \\
\hline Owned & 48495.51 & 772449.5 & 1.00 & 1.00 \\
\hline Rented & 7851.713 & 74550.84 & $2.31(2.25,2.38)$ & $1.58(1.52,1.64)$ \\
\hline other & 7119.112 & 27016.36 & $2.88(2.79,2.98)$ & $2.11(2.04,2.18)$ \\
\hline
\end{tabular}

*Statistically insignificant association at $5 \%$ level of significance

\section{Discussions}

This study indicated that young people aged 15-29 years out-migrated at a higher rate, which could be attributed to search for better educational and employment opportunities and marital arrangements elsewhere since they customarily leave their family homes when they got married. The exceptionally high rate of out-migration among teenagers in this community might be attributed to the influence of peers living in urban areas, often working as shoeshiners and taxi conductors, who might pull their relatives and friends towards their destination urban areas during annual visits to their parents' homes in festivals (Regassa and Yusufe 2009). Males had a higher chance of out-migration from Butajira than females as they could get such jobs in urban centers more easily.

Out-migration was higher among educated in this study. A similar study in five major regions of Ethiopia indicated that educated out-migrants had better living conditions at the place of destination that stimulated the increased rate of out-migration among this group (Mberu 2006) . People with higher levels of education may detach themselves from simple social, cultural and environmental barriers in local areas and be more receptive towards positive external influences. In addition to this, educated migrants have the necessary skills and experience to make a valid decision as to when and where to move by assessing the pros and cons of pull and push factors (Ram and Shin 2007). The destination urban areas where there are better life opportunities could be more receptive to them looking for their experiences. Even if they succeed, the non-educated ones may be making local or short distance moves which could not be correctly measured in this study since short distance moves by Butajira residents were customarily done temporarily in the study community.

The place of origin for the high number of young and educated migrants documented in this study would be negatively affected since they are the ones that have to be heavily engaged in creating work opportunities and leading the economic and social growth in rural Ethiopia, according to the growth and transformation plan of the country(MoFED 2013). On the other hand, if efforts were put in place to organize and coordinate for sharing the skills, experiences and income of out-migrants with their families at the place of origin the negative impact of out-migration on the families left at home will be minimal. There is however little effort in this regards that taps the resources from out-migrants to use it in the development effort in rural Ethiopia.

People who were not currently married were also more likely to move out since they had no social obligations or economic responsibilities forcing them to stay in their birth places. Marriage increases social responsibility and familial ties and deters the chance of out-migration. On the other hand, one or both couples are likely to leave the area of residence during marital dissolution. This study showed higher propensity of out-migration among never married group which could be due to arrangement of 
marriage in a different area or dissolution forcing one of the couple to leave the area, employment or education opportunities elsewhere. Moreover, the second higher probability of out-migration among people who dissolved their union was in agreement with a study done in the Netherlands that showed an increased rate of out-migration for one partner of a couple when dissolution happened (Feijten and Ham 2007). Another study done in Russia indicated that couples who often travelled over long distances had significantly higher rate of union dissolution than couples who did not move or moved only once (Muszynska and Kulu 2007). Thus, marital dissolution might be both the determinant and consequence of migration. Similar studies revealed migration as age, sex and education selective (Kloos 1982, Ezra and Kiros 2001, Zeleza 2002, Fussell and Massey 2004, Quinlan 2005, Mberu 2006, Fleischer 2007, Poveda 2007, Ram and Shin 2007, Regassa and Yusufe 2009, Zorlu 2009). The youth, males and educated were more likely to move out of their usual place of residence (CSA 2006).

Muslims out-number Christians in the study area. The higher chance of out-migration among minority religious groups in the area might be because of the fears over tensions between Christians and Muslims in South-Western Ethiopia, which is adjacent to the study area. Moreover, out-migration rate exceeded among people from religious and ethnic minority groups in sub-Saharan Africa, seeking more security and attracted by their relatives and community groups living in the destination areas (Quinlan 2005).

There was statistically significant difference in the probability of out-migration between rural highlanders and urbanites even after confounding factors were controlled. After allowing for other factors, there were no significant differences in the chance of out-migration between highlanders and lowlanders. However, it had to be recognised that the Butajira DSS sample population consisted of 10 non-contiguous neighbourhoods within the district, and so out-migration in some cases might involve moving from an enumerated area into an adjacent non-enumerated one. Urbanites had better access to media, education and knowledge of opportunities elsewhere which could trigger more out-migration. They could also easily exploit new work opportunities which claimed movement from their neighbourhood by virtue of their physical access.

Rural inequality can influence behaviour and trends in migration(Kirsten and Kirsten 2000). Property ownership could deter African families from migration, at least for economic reasons. Accordingly, ownership of ploughing oxen is considered to be detrimental to the economic growth of rural households in Ethiopia as subsistence farming is the major livelihood. This study indicated that people residing in households without oxen out-migrated slightly less than those with oxen though it was marginally significant when other factors are controlled. This was similar to a study done in Botswana which showed more out-migrations from households owned cattle (Bainame, Letamo et al. 2002). They might be attributed to the fact that rural affluent households might be more prone to outmigration since they could have easily covered their transportation and other migration related expenses until a migrant settles well in the destination area. However, a residential house is another important asset for most Ethiopians. It is relatively easy for rural householders to own their house, whereas the poor in urban areas often live in a house which is rented from the local administration. Individuals living in rented houses had higher propensity of out-migration compared to those living in households' owned houses. Moreover, members of households that lived in a house obtained from relatives free of monthly house rent showed even more likelihood of outmigration probably because they obtained the residential house since they are too poor to pay a house rent. If people did not have an easy to have asset such as a house in rural Ethiopia they could not cope living in the area and would be more prone to the probability of out-migration.

The overall findings, of relatively high rates of outmigration among younger adults and those with education, could be of social significance if the same trends continue. The development and economic progress of relatively rural areas such as Butajira district is unlikely to advance quickly if significant proportions of these key demographic groups leave for other areas. We suggest that local authorities need to consider strategies for retaining these people in their own areas, to safeguard the future well-being of the entire population. Initiatives to facilitate local employment and housing opportunities for younger people would be important in this context.

\section{References}

Bainame, K., G. Letamo and M. RG (2002). The effects of rural inequalities in fertility and migration in Botswana. G. Report. Gaborone, Botswana.

Berhane, Y., S. Wall, M. Fantahun, A. Emmelin, W. Mekonnen, U. Hogberg, A. Worku, M. Molla, N. Deyessa, A. Kumie, D. Hailemariam, F. Enqueselassie and P. Byass (2008). "A rural Ethiopian population undergoing epidemiological transition over a generation: Butajira from 1987 to 2004." Scand J Public Health 36. 
Berhane, Y., S. Wall, D. Kebede, A. Emmelin, F. Enqueselassie, P. Byass, L. Muhe, T. Anderson, N. Deyessa, Y. Gossaye, U. Hogberg, A. Alem and D. Kjerstin (1999). "Establishing an epidemiological field laboratory in rural areas- potential for public health research and interventions. The Butajira Rural Health Programme 1987- 99." Ethiop J Health Dev 13: I-47.

Bilsborrow, R. E. and C. R. Winegarden (1985). "Landholding, rural fertility and internal migration in developing countries: econometric evidence from cross-national data." Pak Dev Rev 24(2): I25-149.

Byass, P., Y. Berhane, A. Emmelin and S. Wall (2003). "Patterns of local migration and their consequences in a rural Ethiopian population." Scand J Public Health 3I(I): 58-62.

Byass, P., Y. Berhane, A. Emmelin and S. Wall (2003). "Patterns of local migration and their consequencies in a rural Ethiopian Population." Scand J Public Health 3I(I): 58-62.

CSA (2006). Report on the 2005 National Labour Force Survey. Addis Ababa, Central Statistical Agency: I-385.

Ezra, M. and G. E. Kiros (200I). "Rural out-migration in the drought prone areas of Ethiopia: a multilevel analysis." Int Migr Rev 35(3): 749-77I.

Feijten, P. and M. V. Ham (2007). "Residential Mobility and Migration of the Divorced and Separated." Demographic Research 17(21): 623654.

Fleischer, A. (2007). "Family, obligrations, and migration: The role of kinship in Cameroon." Demographic Research 16(I3): 41 3-440.

Fussell, E. and D. S. Massey (2004). "The limits to cumulative causation: international migration from Mexican urban areas." Demography 4I(I): I5II7I.

George, M. V., F. Nault and A. Romaniuc (|99|). "Effects of fertility and international migration on changing age composition in Canada." Stat J UN Econ Comm Eur 8(I): I3-24.

Gurumu, E., S. Goldstein and A. Goldstein (2000). Migration, gender and health survey in five regions of Ethiopia: 1998. W. s. s. United Nations Training and Research Project on the interrelations of Migration and Economic Change, Reproductive Health. Addis Ababa, DTRC, Addis Ababa University; and PSTC, Brown University.

Kaushik, M., A. Jaiswal, N. Shah and A. Mahal (2008). "High-end physician migration from India." Bulletin of the World Health Organization 86(I): 40-45.

Kirsten, J. and M. Kirsten (2000). "The effect of rural inequality and fertility and migration: a literature review." Development Southern Africa 17(4): 583602.
Kline, D. S. (2003). "Push and Pull Factors in International Nurse Migration." JOURNAL OF NURSING SCHOLARSHIP 35(2): I07-I I I.

Kloos, H. (1982). "Farm Labor Migrations in the Awash Valley of Ethiopia." International Migration Review I6(1): 133-168.

Massey, D. S. (1990). "Social structure, household strategies, and the cumulative causation of migration." Popul Index 56(I): 3-26.

Massey, D. S. and R. M. Zenteno (1999). "The dynamics of mass migration." Proc Natl Acad Sci USA 96(9): 5328-5335.

Mberu, B. U. (2006). "Internal Migration and household living conditions in Ethiopia." Demographic Research I4(2I): 509-540.

Mekonnen, W. and A. Worku (20II). "Levels and proximate determinants of fertility in Butajira District, South Central Ethiopia." Ethiop. J. Health Dev 25(3): |84-191.

MoFED (20I3). Growth and Transformation Plan: Annual Progress Report for F.Y 201 I/I2, MoFED.

Muszynska, M. and H. Kulu (2007). "Migration and Union Dissolution in a changing socio-economic context: The case of Russia." Demographic Research 17(27): 803-820.

Poveda, A. R. (2007). "Determinants and consequencies of internal and international migration: The case of rural populations in the south of veracruz, Mexico." Demographic Research 16(10): 287-314.

Quinlan, R. J. (2005). "Kinship, Gender and Migration from a Rural Caribbean Community." Migration letters 2(I): I-II.

Ram, B. and Y. E. Shin (2007). "Educational Selectivity of Out-migration in Canada: 1976-198I to 1996200I." Canadian Studies in Population 34(2): 129148.

Regassa, N. and A. Yusufe (2009). "Gender Differentials in Migration Impacts on Southern Ethiopia." Anthropologist I I (2): I29-I37.

Schlottmann, A. M. and H. W. J. Herzog (1984). "Carrier and Geographic Mobility Interactions: Implications for the Age Selectivity of migration." The Journal of Human Resources 19(I): 72-86.

Shamebo, D., A. Sandstrom, L. Muhe, L. Freij, I. Krantz, G. Lonnberg and S. Wall (1993). "The Butajira project in Ethiopia: a nested case-referent study of under-five mortality and its public health determinants." Bull World Health Organ 7I(3-4): 389-396.

Shamebo, D., A. Sandstrom and S. Wall (1992). "The Butajira rural health project in Ethiopia: epidemiological surveillance for research and intervention in primary health care." Scand J Prim Health Care I0(3): 198-205. 
Ullah, A. (2004). "Bright City Lights and Slums of Dhaka City: Determinants of rural-urban migration in Bangladesh." Migration letters $\mathrm{I}(\mathrm{I})$ : 26-4I.

UNDP (20I4) "Country Economic Brief: Ethiopia." Analysis.

Zeleza, P. T. (2002). "Contemporary African Migrations in a Global Context. The African "Brain Drain" to the North: Pitfalls and Possibilities." African Issues 30(I): 9-I4.
Zhang, X., Z. Wu and L. Chen (1997). "Age difference among the rural labor force in interregional migration." Chin J Popul Sci 9(3): |93-20|.

Zorlu, A. (2009). "Ethnic Differences in Spatial Mobility: The Impact of Family Ties." Popul. Space Place 15(4): 323-342. 